\title{
Submental route of endotracheal intubation; a better solution in cases of multifacial fractures
}

\author{
Manish Banjare ${ }^{1}$, Deepak Kumar Sharma ${ }^{2}$ \\ Associate Professor ${ }^{1}$, Resident Anaesthesiologist ${ }^{2}$, Department of Anaesthesiology; M.G.M. Medical \\ College and M.Y.Hospital, Indore, India.
}

*Corresponding author : manish_banjare@yahoo.co.in

\begin{abstract}
Complex maxillofacial surgeries have always been a challenge for anaesthesiologists, where oral cavity is the main field of surgery and dental occlusion is a prerequisite. In such conditions, anaesthesiologists opt for nasotracheal intubation. Some patients however may require simultaneous free nasal field where nasal fracture and cerebrospinal fluid leak may contraindicate nasotracheal intubation. Tracheostomy has long been the sole answer to these problems. Here submental approach for tracheal intubation can be an apt alternative.
\end{abstract}

In this approach the endotracheal tube is introduced along a diverted route through the floor of mouth via a tunnel made in the submental region. We opted for this technique in four patients posted for fixing facial bones, requiring both nasal and oral fields and the results have been satisfying. In two patients we used one tube method. In the other two patients, we used double tube method where another tube was brought intraoral through submental incision and the first tube was replaced.

This technique avoided the need for tracheostomy and provided a safe airway without causing significant morbidity. Thus submental approach for tracheal intubtion can be a better solution to various problems arising in cases of complex maxillofacial surgeries. We also found that double tube method was safer and even easier than one tube method for submental intubation.

Keywords : submental route, maxillo facial surgery, intubation

\section{Introduction}

Presence of mid facial or pan facial fractures with nasal and mandibular fractures raises various challenges to both surgeons and anaesthesiologists. Tracheostomy is an excellent method to establish the airway in such patients both routinely and in an emergency. Altemir for the first time in 1986 described sub mental route for tracheal intubation in such cases. Since then it has become very popular and various modifications have been introduced from time to time. We describe our experience with four patients having complex mid facial fractures.

\section{Case Report}

This is a study of four cases (20 to 45 yrs age) with ASA grade $1 / 2$ and good mouth opening (Mallampati score 1/2) who had Le forte two and three type fractures with nasal bone fracture .Two of them had evidence of cerebrospinal fluid rhinorrhoea. These patients were posted in routine operation theatre for fixation of multi facial fractures (since Jan. 2010 to Dec.

2010).We opted for one tube method in two patients and two tube method in two patients for submental intubation.

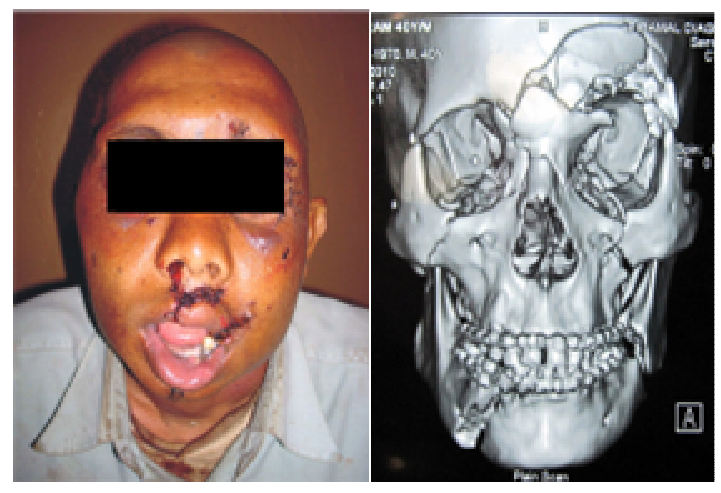

Figure1- one of our patients with multi facial fractures and his 3D scan 
Scenario 1- After full preparation and premedication with injection glycopyrrolate 0.2 $\mathrm{mg}$, injection ondansetron $4 \mathrm{mg}$ and injection ranitidine 50mg, injection midazolam $1.5 \mathrm{mg}$, patients were shifted to operating theatre. Intravenous lines were secured and dextrose containing fluid was started. After preoxygenation with $100 \%$ oxygen for five minutes and making sure that bag-mask ventilation was possible, induction was done using injection fentanyl $2 \mathrm{mcg} / \mathrm{kg}$ i.v., injection propofol $2 \mathrm{mg} / \mathrm{kg}$ i.v. and injection succinylcholine $2 \mathrm{mg} / \mathrm{kg}$ i.v. Orotracheal intubation was done using 36 French gauge cuffed flexometallic endotracheal tube and ventilation was started using a Bain circuit. A $2 \mathrm{~cm}$ skin incision was made just medial and parallel to the ramus of the madible by the surgeon, staying as far away from the fracture site as possible, under full asepsis. This was deepened using blunt dissection up to the oral cavity. The breathing circuit was detached from the tube and universal connector of the flexometallic endotracheal tube was removed. The pilot balloon followed by the outer end of the tube was brought out using an artery forceps through the incision, while stabilizing the tracheal end of the tube using a Magill's forceps. Connector followed by Bain circuit was reattached to the tube and bilateral air entry was checked and the tube was fixed using skin sutures and anaesthesia continued with $\mathrm{O}_{2}$ and $\mathrm{N}_{2} \mathrm{O}$ in the ratio of $40: 60 \%$, isoflurane and atracurium $(0.08 \mathrm{mg} / \mathrm{kg})$.

At the end of the surgery, breathing circuit was detached from tube and the pilot balloon and the outer end of the tube was pulled back into the oral cavity, stabilizing the tracheal end with Magill's forceps and thus sub mental intubation was converted into orotracheal intubation. After return of oropharyngeal reflexes, reversal was done with injection neostigmine $0.05 \mathrm{mg} / \mathrm{kg}$ and injection glycopyrrolate $0.01 \mathrm{mg} / \mathrm{kg}$. Extubation was done uneventfully in the operating theatre. External skin incision was closed by sutures, leaving mucosal incision untouched. Proper postoperative care was given to the skin wound.

Scenario 2- In two other cases, where we used the double tube method the technique was slightly different. After induction in a similar way, conventional orotracheal intubation was done with appropriate sized disposable cuffed endotracheal tube and ventilation started using a
Bain circuit. A two centimeter wide tunnel was made in the same way in the sub mental region under full asepsis. After checking for its balloon and connector, the tracheal end of an appropriate sized flexometallic endotracheal tube was pushed gently into the oral cavity with rotatory motion, taking care not to rupture the balloon. After giving proper relaxation, previous tube was removed and the new tube, which was brought into the oral cavity through the sub mental incision, was passed through the vocal cards using a Magill's forceps. Breathing circuit was then attached to this tube and anaesthesia continued with this new tube. After checking bilateral air entry, tube was fixed using skin sutures. At the end of the surgery reversal was done after return of proper reflexes. Extubation was done uneventfully through the external skin incision only. Skin wound was closed using suture with full asepsis.

The patients were followed up until they were discharged from the hospital in good health. The postoperative scar was fairly acceptable.

\section{Discussion}

Facial and maxillary surgeries aim at fixation of various bones to achieve dental occlusion as a basic requirement, Orotracheal intubation would hinder the surgical field in these cases. Here nasotracheal intubation is a simple choice. But in some cases nasal route cannot be attempted because of presence of nasal bone fractures or skull base fractures, evidence of CSF rhinorrhoea, keeping in view the inherent risks of meningitis and deformed anatomical passage.

In such cases the anaesthesiologists are left with either a tracheostomy; ${ }^{1}$ which itself carries morbidities like haemorrhage, subcutaneous emphysema, tracheomalacia, tracheal stenosis or erosions, infections, pneumothorax, pneumomediastinum, recurrent laryngeal nerve palsy and problems with decanulation and scar; or submental intubation $2,3,4$ and in some cases retro molar route for intubation. $^{5}$

Placing the tube in the retro molar space, after conventional orotracheal intubation would serve the purpose to some extent but the space may not be adequate, especially in older 
patients. Further the bulky tube may hinder the surgical field.

Submental tracheal intubation was first described by Altemir in 1986. Here a diverted passage is made for endotracheal tube in sub mental region via skin, subcutaneous tissue by blunt dissection through the muscles of the floor of the mouth, chiefly myolohyoid, taking care not to damage the structures in the region. After conventional orotracheal intubation, outer end of the tube is brought out of the oral cavity through the tunnel leaving behind a free oral cavity and allowing dental occlusion. This diversion of the ETT serves all purposes in cases requiring both oral as well as nasal access. The advantages are that it leaves both oral and nasal fields free for the surgeon and avoids need for tracheostomy and nasal intubation along with their complications. There is also no connection to cerebrospinal fluid leak or disturbed anatomy of upper airway. It is safe, quick and easy to perform, good fixation of tube can be achieved and a secure airway can be established. There is minimal scaring and complications.

The site of skin incision can be median or para median. There can be more bleeding in paramedian approach due to injuries to the submental vessels. A horizontal incision will lead to a less visible scar. Amin et al. suggested the incision at one-third way from the symphysis menti to the angle of mandible, close to the lingual surface of the mandible to avoid damage to the submental structures lying medially.

Other indications where this technique has been used are skull base surgeries ${ }^{6}$, orthognathic surgeries, aesthetic plastic surgery, rhinoplasty procedures, as an alternative to short term tracheostomy.

This procedure however is not totally free from complications. There may be difficulty in passing the tube through sub mental tunnel and this may take time causing fall in oxygen saturation. Accidental displacement and extubation can occur, which may be difficult to manage. Rupture of tube or pilot balloon may occur. Excessive bleeding may occur specially with paramedian approach. Injuries to lingual nerve, submandibular duct, sublingual glands and infection and orocutaneous fistula or sinus are reported. Submental scar, however is small and acceptable.

To avoid these problems, various modifications have been advocated from time to time. Chances of desaturation due to difficult passage of tube through submental tunnel and accidental damage to tube can be avoided using double tube method.

In restricted mouth opening, submental intubation has been described using pharyngeal loop assembly ${ }^{7}$ in retrograde fashion.

Contraindications for this technique are bleeding tendencies, reduced mouth opening, deformed submental space anatomy. An adequate sized good quality reinforced endotracheal tube and adequate mouth opening are mandatory for this procedure.

\section{Result}

The submental technique of tracheal intubation serves various purposes in above described conditions. It provides safe and easy airway with free surgical field without causing much morbidity. In our cases, no difficulty was encountered during passing the tube and pilot balloon across the submental passage or detaching and reattaching the universal connector to the tube. There was minimal bleeding and there were no episodes of fall in oxygen saturation.

Damage to the tubes did not occur. ETT suction was easy to perform. There were no episodes of displacement of tube or accidental extubation. Our patients could be extubated in theater uneventfully. The skin scar was minimal. Procedure was easy to perform, took average 67 minutes to be accomplished and no intraoperative or postoperative complications occurred.

Double tube method, however, seems to be safer, as in event of any mishap; like difficulty in passing the tube through the tunnel, ventilation can be continued with the first tube; thus chances of hypoxia are rare.

\section{References}

1. Chew JY, Cantrell RW.

Tracheostomy,complications and their management. Arch Otolaryngol. 1972;96:538-545 http://dx.doi.org/10.1001/archotol.1972.0077009081 $\underline{6008}$

2. Altemir FH. The submental route for endotracheal intubation. J Maxillofac Surg. 1986;14:64-65. 
http://dx.doi.org/10.1016/S0301-0503(86)80261-2

3. Paetkau D, Strand M, Onc B. Submental

orotracheal intubation for maxillofacial surgery.

Anesthesiology. 2000;92:912-914.

http://dx.doi.org/10.1097/00000542-200003000-

$\underline{00063}$

PMid:10719991

4. Chandu A, Smith ACH, Gebert R. Submental intubation: an alternative to short-term tracheostomy.

Anaesth Intensive Care 2000; 28: 193-5

PMid:10788973

5. Martinez-Lage JL, Eslava JM, Cebrecos AI,

Marcos O. Retromolar intubation. J Oral Maxillofac

Surg. 1998;56:302-306.

http://dx.doi.org/10.1016/S0278-2391(98)90103-3

6. Sekkar LN, Janeka IP. Surgery of the cranial base tumors. New York: Raven Press. 1993:235-240.

7. Bahr W, Stoll P. Nasal intubation in the presence of frontobasal fractures. J Oral Maxillofac Surg. 1992;50:445-451.

http://dx.doi.org/10.1016/S0278-2391(10)80312-X

$* * * * * * * * * * * * * * * * * * * * * * * * * * * * * * * * * * * * * * * * * * * * * * * * * * * * * * * * * * * * * * * * * * * * * * * * * *$

\section{THE COLLEGE OF ANAESTHESIOLOGISTS OF SRI LANKA}

\section{POSTER COMPETITION FOR SASHIDHARAN PRIZE}

1. The prize is open to all medical practitioners holding an appointment in anaesthesia

2. The posters will be judged on their content, originality and presentation.

3. The maximum size of the poster should be 25 " $x 22$ " cm and the poster should be oriented with the long axis vertically (portrait).

4. The decision of the panel of judges will be final.

5. The prize will not be awarded if the judges decide the submissions are not up to standard.

(Those who wish to submit posters are asked to read an excellent article by Professor Robert Sneyd on "How to make a poster" in Anaesthesia News December 2009 Issue 269 pp 25-26. A copy of the paper could be sent by email if a request is made to the College office)

Those who wish to submit posters for the prize competition should submit an abstract of the contents of the poster on or before $31^{\text {st }}$ October 2012

College of Anaesthesiologists of Sri Lanka, No 44/5A, Gnanartha Pradeepaya Mawatha, Colombo 8, Telephone: (11)2672327, Fax:(11)2672327,E mail: anascol@ sltnet.lk.

Web site: www.srilanka-anaesthesia.com 